\title{
Navigating Allyship through Indigenization, Decolonization, and Reconciliation: Perspectives from Non-Indigenous Pharmacy Educators
}

Larry Leung, BSc(Pharm), RPh; Jason Min, BSc(Pharm), RPh

Faculty of Pharmaceutical Sciences, University of British Columbia

\begin{abstract}
As pharmacy schools across Canada and North America work towards authentic and meaningful curriculum and learning opportunities in Indigenous health and cultural safety, the conversation of "why" we need to do this has become clearer, but the task of "how" we do this remains challenging. This curricular transformation can be increasingly more complex to navigate as a non-Indigenous ally and pharmacy educator. Defining your role as an ally is deeply personal and critically important, as it can transform based on the collaborative work undertaken with Indigenous partners and communities. The purpose of this article is to share perspectives gained over years of experience and practical applications of allyship through the lens of three key separate, but interconnected concepts indigenization, decolonization, and reconciliation.
\end{abstract}

Key words: Allyship; indigenous; cultural safety; indigenization; decolonization; reconciliation

\section{Introduction}

Canada's national Truth and Reconciliation Commission (TRC), completed in 2015, was a wake-up call for Canadians and a pivotal moment in history for pharmacists and pharmacy educators. ${ }^{1}$ Among the TRC's 94 calls to action was the mandate to better train health care professional students to address health inequities experienced by Indigenous ${ }^{\mathrm{a}}$ Canadians. $^{1}$ Creating authentic skills-based curricula and learning opportunities in intercultural competency, conflict re-solution, human rights, and anti-racism was recognized as a critical mechanism for improving health professions education and the overall health and well-being of Indigenous people and communities. ${ }^{1}$ In response to the TRC, many post-secondary health profession programs, like the Faculty of Pharmaceutical Sciences at the University of British Columbia, have placed greater emphasis on Indigenous health and cultural safety in policies and strategic planning. ${ }^{2}$ This is a necessary, yet challenging step for educators grappling with the implications of the TRC's mandate for curriculum change. Working at the intersection of deeply rooted Western medical and educational practices and Indigenous ways of knowing, learning and healing has become a primary obligation and responsibility for all pharmacy educators. While the conversation of why we have to do this is clear, the task of how we make change remains uncertain and complex and is inescapably upon us.

We (the authors) identify as pharmacists, educators, and nonIndigenous allies of Asian ancestry living in Vancouver, British Columbia (BC), Canada. BC, on the west coast of Canada, is home to an incredible diversity of Indigenous communities with

Corresponding author: Larry Leung, BSc(Pharm), RPh

Faculty of Pharmaceutical Sciences

University of British Columbia

Email: larry.leung@ubc.ca unique cultures, traditions, and languages (close to 30 First Nations languages and 60 dialects). ${ }^{3,4}$ As educators, we work at the University of British Columbia's Vancouver campus, which is located on the traditional, ancestral, and unceded territory of the Musqueam people.

Over the past 9 years, we have had the privilege of working directly with many of $\mathrm{BC}^{\prime}$ s urban, rural, remote, and isolated Indigenous communities in academic and research capacities, fostering meaningful and respectful collaborations along the way. These collaborations include co-developing core and elective Indigenous health and cultural safety curricula in the pharmacy program, co-creating transformative elective practicum opportunities in Indigenous communities, and conducting ethical community-based research on medication and health practices. These experiences have been both the most rewarding and challenging aspects of our academic careers and the many lessons learned along the way have shaped our views on allyship. Defining our role as an ally has been critically important and has continued to transform based on three key concepts - indigenization, decolonization and reconciliation. We want to discuss our perceptions and practical applications of allyship through the lens of these concepts and hope that through this process, readers can also reflect and refine their own role as an ally to Indigenous partners and communities.

\footnotetext{
a The Truth and Reconciliation Commission of Canada (TRC), was established in 2008 and commissioned as part of the Indian Residential Schools Settlement Agreement. Over 6 years gathered written and oral histories of approximately 7000 residential school survivors across Canada. Residential schools operated in Canada between the 1870s and the 1990s with the goal of assimilating Indigenous peoples into mainstream Canadian society. The last residential school closed in 1996. The final TRC report was published in June 2015 and was accompanied by 94 Calls to Action, calling on all Canadians, all levels of government, educational institutions and others to learn and share historical truths and engage in reconciliation with Indigenous peoples. ${ }^{1}$
} 


\section{Defining the Role of an Ally}

The term "ally" has been around for many years and at times, seems to have lost its lustre and original intent and meaning. ${ }^{5,6}$ Instead of being used to identify one's role within a collective struggle, it has been generalized inappropriately as a badge for non-Indigenous people to wear as a symbol of their commitment. ${ }^{5}$ As educators, we know that being an ally is a commitment to the lifelong practice of building relationships with Indigenous partners and honouring those relations by meaningfully collaborating on the development and implementation of Indigenous-focused curricula and research. Operationalizing allyship will vary between institutions and Indigenous communities. However, it will consistently be rooted in disruptive, but necessary pedagogical practices of indigenization, decolonization, and reconciliation. Meaningful allyship requires a shift in both thinking and practice, disrupting schools and programs, in not only what Indigenous curriculum is being taught, but how and why. Although these three concepts have had various definitions and are sometimes (incorrectly) used interchangeably, these are very separate, but interconnected processes. ${ }^{7}$

\section{Indigenization}

Indigenization refers to the process of integrating Indigenous ways of knowing and learning with current Western knowledge systems, not just the addition of new Indigenous content or activities. ${ }^{7}$ Indigenization can obviously be a challenge in pharmacy and other health programs that focus on evidencebased care approaches. Indigenization requires meaningful input from strong Indigenous voices as a way to supplement the pharmacy-specific knowledge of non-Indigenous faculty. Deciding where and how to start can be elusive, as there are multiple approaches that can be taken. For us, this meant the creation of an advisory committee with majority representation from external Indigenous experts and scholars including Elders, traditional knowledge keepers, Indigenous community members, and health administrators. This advisory committee provided leadership, guidance, and decision-making on specific content areas for an Indigenous health elective course, including the incorporation of different instructional delivery formats focused on story-telling and relationship-building, reflective assessment methods, and talking circles. Treating the advisory committee members as true experts also meant providing honoraria at rates equivalent to other nonIndigenous external expert consultations and reimbursing travel. It is important to recognize indigenization as a collective responsibility that requires our active participation to better strengthen Indigenous voices.

One method that we found particularly effective was pairing an external Indigenous expert with a non-Indigenous faculty member for in-class activities or guest lectures. Students resonated with the expert knowledge and perspectives provided by the Indigenous voice, and benefitted from the relevance and application to pharmacy practice through the ally. As an example, we co-developed a session on cultural safety practices, which was delivered through the sharing of stories related to experiences of patients using traditional medicines and methods of healing. The story-telling format used little to no presentation slides, which helped to create a safe and open environment for students to actively listen to the stories shared, ask questions and engage in discussion. One method that our Indigenous experts usually consider is opening with a prayer, song, or smudging ceremony, which creates an environment where students are out of their chairs and engaged. During the story-telling period, the traditional knowledge keeper shared about her community's social organization and the importance of cedar and fish as part of culture and medicine. As non-Indigenous allies, we communicated with students the struggles we experienced breaking down the barriers of our Western-dominant views of traditional medicines and balancing our knowledge systems with Indigenous ways of knowing and healing. These stories proved impactful for our students, as they learned from a traditional knowledge keeper and were provided a realistic scenario of a pharmacist balancing this knowledge with evidence-based medicine to better provide care to their patient. We also found that dialogue and rapport created between the two educators modelled respectful and ethical engagement, which created valuable and serendipitous learning lessons. This story-telling format was used throughout the course and assessment of learning involved reflexive photography, a visual art-based reflection, which was codeveloped and linked to course objectives and competencies. Prior to and following these sessions, students had the opportunity to provide their own personal stereotypes and thoughts on traditional medicine practices. Our traditional knowledge keeper found these student perspectives helpful, as understanding how pharmacy students viewed traditional medicines better informed her on methods that might change perceptions through the sharing of Indigenous perspectives.

The greatest threats we have seen on genuine indigenization have been tokenism and complacency. These are two concepts that are relatively easy to understand and even easier to participate in, consciously or not. With indigenization at the forefront of many programmatic and institutional strategic plans, many non-indigenous allies may treat this concept as simply a symbolic effort requiring a checklist approach. Others may grow complacent and delegate responsibilities to Indigenous supporting units and local Indigenous experts without providing culturally-appropriate support. Anecdotally, we have heard Indigenous Elders share that many Faculties and programs will shift all responsibility of content creation, delivery, and assessment to Indigenous partners. Providing culturally-appropriate support can be highly individualized and, in the past, may have included developing new methods for student assessment (reflections over traditional multiple choice questions), reimbursing the cost of tobacco or sage as ceremonial sacred medicines, and other Indigenous 
appropriate protocols for talking circles and smudging ceremonies.

\section{Decolonization}

Decolonization refers to the process of changing existing colonial structures and frameworks in our Western systems and values. $^{7}$ Our role as an ally begins with recognizing and identifying the dominant and core structures at the institution that need to be deconstructed and rebuilt. We are often asked what our approach is in decolonization, as it can be difficult to see past the seemingly impossible task of deconstructing the system. This can be especially challenging as educators, since we inherently benefit from the colonial structure of universities through our salaries, funding opportunities, and professional development. True decolonization requires action at all levels including the course-level (e.g. through Indigenous teaching and assessment methods), the faculty-level (e.g. Indigenous student admission policies, Indigenous initiatives in strategic plans, Indigenous faculty member hiring), and the institutionallevel (e.g. centralized support systems for Indigenous grants and tenure/promotion metrics in alignment with Indigenous measures of success).

For us, the natural starting place was at an individual level, which is where we all have the ability to control. This meant learning, practicing, and reflecting on cultural safety and humility to enhance self-identification of personal biases, systemic racism, and privileges. ${ }^{8}$ As you might expect, the process of understanding our own inherent barriers revealed new learning opportunities for us. One example was better understanding Indigenous data ownership and governance in the context of research. The First Nations Information Governance Centre in Canada offers a course on First Nations principles of Ownership, Control, Access, and Possession (OCAP) of data and clarifies appropriate protocol for researchers. ${ }^{9}$ Applying OCAP principles and those of ethical community engagement in our grant applications for Indigenous-related projects looked very different than our nonIndigenous projects. Specifically, we dedicated significant portions of our budget request to travel for face-to-face meetings with Indigenous partners, paying for Indigenous ceremonial medicines as part of a project start and end gathering, and disseminating findings in community-specific ways (e.g. brochures, online material) rather than peerreviewed journals. We experienced potential funders who challenged and sought to undermine OCAP principles, particularly around the ownership and possession of data by participating Indigenous individuals, families, or communities. Our approach has focused on organically expanding the advocacy of these issues and aligning projects with other faculty or institutional priorities. Having conversations with grant funders about these issues provides opportunities to educate others and also seek advice on aligning a proposal with funding priorities, while still honoring OCAP principles. We often reflect that we have been in a unique position of requesting funding from a colonial structure, while simultaneously attempting to deconstruct it.

The complexities of decolonizing faculty and institutional systems are expected. Leadership on strategic plans, policies, hiring, and other written commitments are all enablers for this work. Examples of this are readily available and can be helpful for other institutions to review and seek inspiration. ${ }^{10,11}$ Competing interests for other programming and the desire for a balanced representation among other "populations of interest" are common misconceptions. The often-quoted term of "equity does not mean equality" stands true in this argument, with decolonizing our systems as a necessary means to begin considering equality for Indigenous health. The reality of prevalent health disparities for Indigenous peoples today and the corresponding lack of faculty and institutional support to adequately train our students to address this is contributing to the inequities in health of our patients we seek to care for.

\section{Reconciliation}

Reconciliation is the process of accepting our shared history of colonialism and Indigenous cultural genocide in Canada and moving towards tangible actions to strengthen the relationships between Indigenous peoples and non-Indigenous allies. ${ }^{7}$ Denial, apathy, guilt, and anger can all be emotions for faculty and students who navigate this collective responsibility of reconciliation. As pharmacy educators, we must also be prepared to contend with enthusiastic saviourism that can be damaging to reconciliation efforts. As allies, it is important to recognize that we are not the experts in Indigenous health, which lies directly with our Indigenous partners. Thinking about ourselves as experts creates a power differential, where we, as privileged health professionals and educators, are here to "help" or "save" the people we seek to collaborate and serve with. This is against the core principle of patient-centered care that we teach our students. To provide a safe space for the conversations to occur, it is important to be prepared to address these challenging environments with appropriate knowledge, encouragement, and skill. Faculty development workshops can be incredibly helpful to build your knowledge base, as well as the growing number of excellent fiction and non-fiction works by Indigenous writers, such as Indigenous Relations: Insights, Tips and Suggestions to Make Reconciliation a Reality by Bob Joseph and Cynthia F. Joseph and They Called Me Number One: Secrets and Survival at an Indian Residential School by Bev Sellars. These are two examples of books used not only for our own personal reconciliation journey, but also as part of book club with our student learners.

In exploring potential collaborations with Indigenous partners, part of our reconciliation approach is based on the wellestablished 4 R's framework of Respect, Relevance, Responsibility, and Reciprocity. ${ }^{12}$ We must respect Indigenous knowledge, cultures, and practices, ensure student learning is relevant to Indigenous ways of knowing and being, and take responsibility of upholding these principles and values. The final 
" $R$ ", reciprocity, has been one of the most important pieces that our Indigenous partners have highlighted, as it calls for tangible and sustainable actions toward reconciliation. Reciprocity calls for a truly community-driven approach to the engagement and relationships in academia and research. This is to ensure that the outputs, products, and deliverables ultimately benefit not only the Faculty, program, and students, but more importantly, the individuals, families, and communities we serve.

In our experience, reciprocity involves prioritizing an academic or research project based on Indigenous community preferences rather than current pharmacy trends or gaps. This also means asking ourselves many times throughout a project "what does this work mean for our Indigenous partners now and tomorrow?" To achieve this, we work closely with partners to create collaborative measures of success and performance. Institutional measures of success are well known to us: grant dollars received, publications, and teaching and service hours. However, measures of success for partners may be deeply rooted in personal reconciliation of prior injustices. In past projects, measures of success for our partners have included the number of conversations and in-person visits we have with community members, community-based resources created, and access to educational material to local healthcare providers and community members. For example, with one community partner, our main measure of success was to identify the top 5 Indigenous traditional plant medicines used in the community, including collating information on how to find and harvest each plant, how to prepare a product, and how to use it therapeutically. The pharmacy contribution was to collate safety data on each plant, including interactions with Western medications. This information was then translated from English to the traditional language for the purposes of knowledge dissemination in the community. To understand the impact, we often conduct town halls, catered events, or talking circles to present tangible outputs with the community.

\section{Conclusion}

It's important to note that these concepts exist on a continuum, and examples presented are simply the first steps of many that must be taken. Although these three concepts are unique, they all share the core foundation of the need to foster collaborations built on mutual respect and using a communitydriven approach to improve how pharmacy academia and research can provide meaningful impact for Indigenous communities. As pharmacy programs continue to work towards these important concepts, the role of non-Indigenous allies has become clearer. Regardless of where you or your program is in the journey of indigenization, decolonization, and reconciliation, there are many first-steps that can be taken to improve. How you do this may look different than us, but collectively we can continue to challenge the academy and build on what has already been accomplished.
Conflicts of Interest: None

Financial Support: None

Acknowledgements: We acknowledge that the UBC Vancouver campus is located on the traditional, ancestral and unceded territory of the Musqueam people.

With sincere gratitude for the years of support and resources made available to us at UBC by the Centre for Excellence in Indigenous Health, the Indigenous Foundations Project, and the First Nations \& Indigenous Studies Program.

The First Nations Health Authority in BC for the years of collaboration, leadership, and support to improve pharmacist services.

Dr. Simon P. Albon, PhD, Professor of Teaching, Faculty of Pharmaceutical Sciences, University of British Columbia, for his support and guidance of our indigenization, decolonization, and reconciliation efforts in the pharmacy program.

\section{References}

1. Truth and Reconciliation Commission of Canada: Calls to Action. Truth and Reconciliation Commission of Canada. Available: http://trc.ca/assets/pdf/Calls_to_Action_English2.pdf . Accessed January 4, 2020.

2. Faculty of Pharmaceutical Sciences, University of British Columbia. 2017-2020 Strategic Plan: Catalyst for Change. Available: https://pharmsci.ubc.ca/sites/pharmsci.ubc.ca/files/ Online\%20Version_Catalyst\%20for\%20Change_UBCP S\%20SP\%2017-22.pdf. Accessed January 4, 2020.

3. B.C. First Nations and Indigenous People. Welcome British Columbia. Available:

https://www.welcomebc.ca/Choose-B-C/ExploreBritish-Columbia/B-C-First-Nations-IndigenousPeople. Published 2019. Accessed January 4, 2020.

4. First Peoples' Language Map of BC. Language Map of British Columbia. Available: https://maps.fpcc.ca/. Updated 2019. Accessed January 4, 2020.

5. Lamont A. Guide to Allyship. Available: http://www.guidetoallyship.com/. Accessed Feburary 4, 2020.

6. Montreal Urban Aboriginal Community Strategy Network. Indigenous Ally Toolkit. Available: https://physiotherapy.ca/sites/default/files/indigeno us_ally_toolkit_en.pdf. Accessed January 4, 2020.

7. Antoine A, Mason R, Mason R, Palahicky S, Rodriguez de France $C$. Indigenization, Decolonization, and Reconciliation. In: Pulling Together: A guide for Indigenization of post-secondary institutions. Pressbooks, ed. A professional learning series. BCcampus; 2018:6-8. Available: https://opentextbc.ca/indigenizationcurriculumdevel opers/. Accessed January 4, 2020. 
8. First Nations Health Authority. FNHA's Policy Statement on Cultural Safety and Humility. Available: https://www.fnha.ca/Documents/FNHA-PolicyStatement-Cultural-Safety-and-Humility.pdf. Published June 24, 2016. Accessed January 4, 2020.

9. First Nations Information Governance Centre. The First Nations Principles of OCAP ${ }^{\circledR}$. Available: https://fnigc.ca/ocap. Updated 2019. Accessed January 4, 2020.

10. University of Regina Office of Indigenization. Available: https://www.uregina.ca/indigenization. Accessed January 4, 2020.

11. University of British Columbia Office of the President. Statement of Apology. Available: https://president.ubc.ca/letter-to-thecommunity/2018/04/09/statement-of-apology. Updated April 9, 2018. Accessed January 4, 2020.

12. Kirkness VJ, Barnhardt R. First Nations and Higher Education: The Four R's - Respect, Relevance, Reciprocity, Responsibility. J Am Indian Educ; 30(3):115. 